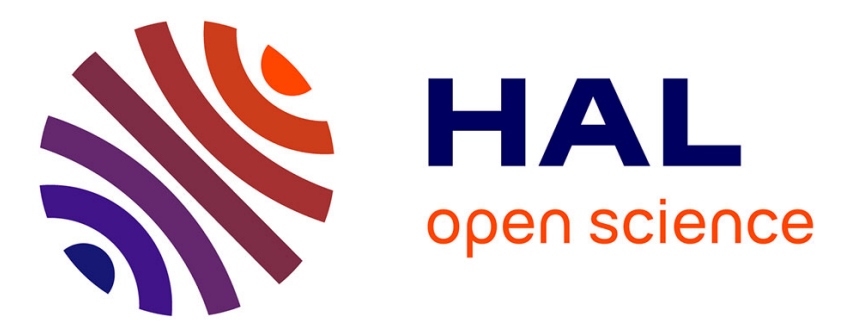

\title{
BMP-2 Incorporated in a Tricalcium Phosphate Bone Substitute Enhances Bone Remodeling in Sheep
}

\author{
Uwe Maus, Stefan Andereya, Sascha Gravius, Jörg A.K. Ohnsorge,
} Christopher Niedhart, Christian H. Siebert

\section{- To cite this version:}

Uwe Maus, Stefan Andereya, Sascha Gravius, Jörg A.K. Ohnsorge, Christopher Niedhart, et al.. BMP2 Incorporated in a Tricalcium Phosphate Bone Substitute Enhances Bone Remodeling in Sheep. Journal of Biomaterials Applications, 2008, 22 (6), pp.559-576. 10.1177/0885328207083311 . hal00570786

\section{HAL Id: hal-00570786 \\ https://hal.science/hal-00570786}

Submitted on 1 Mar 2011

HAL is a multi-disciplinary open access archive for the deposit and dissemination of scientific research documents, whether they are published or not. The documents may come from teaching and research institutions in France or abroad, or from public or private research centers.
L'archive ouverte pluridisciplinaire HAL, est destinée au dépôt et à la diffusion de documents scientifiques de niveau recherche, publiés ou non, émanant des établissements d'enseignement et de recherche français ou étrangers, des laboratoires publics ou privés. 


\title{
BMP-2 Incorporated in a Tricalcium Phosphate Bone Substitute Enhances Bone Remodeling in Sheep
}

\author{
Uwe Maus,* Stefan Andereya, Sascha Gravius, \\ JÖRG A. K. OHNSORGE AND CHRISTOPHER NIEDHART \\ Department of Orthopedic Surgery, University of Aachen, Pauwelsstr \\ 30, D-52074 Aachen, Germany \\ CHRISTIAN H. SIEBERT \\ Orthopaedic Clinic I, Annastift e.V. Anna-von-Borries-Str. 17 \\ $D$-30625 Hanover, Germany
}

\begin{abstract}
Bone morphogenetic protein-2 (BMP-2) is a well-known osteoinductive protein, which requires a carrier for local application. As an alternative to the previously described carriers, an in situ hardening, resorbable, and osteoconductive $\beta$-tricalcium phosphate cement (TCP) is tested. Trepanation defects in the bovine distal femoral epiphysis are filled with a composite consisting of TCP and $200 \mu \mathrm{g}$ rhBMP-2 $2 \mathrm{er}^{3} \mathrm{TCP}$, autologous bone graft, pure TCP, or left empty. A radiological follow-up is performed after 7 weeks and 3 months. The sheep are euthanized and bone samples are analyzed by microradiography, histology, and histomorphometry. Microradiography and histology show similar results for pure TCP and the composite. The defects are filled with trabecular bone and newly formed bone is in close contact with the remaining TCP-particles. The majority of the cement is resorbed, in the composite group the amount of remaining cement particles is reduced. Defects treated with autologous bone graft are filled completely, while untreated defects shows only a small amount of bone originating from the rim of the defect. Histomorphometry of the defects treated with pure TCP shows a significantly increased bone content in comparison to defects treated with the composite or
\end{abstract}

\footnotetext{
*Author to whom correspondence should be addressed. E-mail: umaus@ukaachen.de Figures 4 and 5 appear in color online: http://jba.sagepub.com
} 
autologous bone graft. Analysis of the remaining cement particles shows significantly less cement in the TCP/rhBMP-2 group in comparison to pure TCP. The sum of bone and cement content in the rhBMP-2 group shows amounts comparable to the calcified structures found following autologous bone grafting. The addition of rhBMP-2 to the TCP leads to faster remodeling of the defect comparable to autologous bone graft, while defects treated with pure TCP are not completely remodeled.

KEY WORDS: BMP-2, bone substitute, TCP, calcium phosphate, osteogenesis, osteoinduction, osseous defect.

\section{INTRODUCTION}

7 he operative treatment of large bone defects remains a challenge 1 for orthopedic surgeons. Autologous bone grafting is considered to be the golden standard in reconstructive bone surgery due to its superior osteogenic potential compared to allogenic transplants [1,2]. But the amount of autogenous graft available is limited. The graft harvest lengthens the operation and can be associated with adverse effects, such as bleeding, pain, and infection [3-5]. Allogenic bone material carries the potential risk of infection by a variety of bacteria and viruses including HIV or hepatitis. Due to these drawbacks inorganic composites are of special interest as a bone substitute. The artificial graft must be made of a three-dimensional porous material to induce bone formation and osteoconduction. Calcium phosphate materials, like hydroxyapatite (HA) and tricalcium phosphate (TCP) are classified as bioactive ceramics and have been widely used for the reconstruction of bone defects. Calcium phosphate materials provide a mineral phase similar to bone, as well as excellent osteoconductivity. To allow for a complete restitution of osseous defects, bone substitutes should be resorbable and be continuously replaced by newly formed bone [6,7]. Resorption of TCP has been shown to be superior to HA, while the mechanical stability of TCP is lower [8].

Bone substitutes are available in different shapes and sizes. But, with the exception of granules, the adaptation of the material to bone cavities or defects is difficult because of their brittleness. This leads to gaps between the implanted material and the surrounding bone, which may lead to instability and pseudoarthrosis. This has led to the development of in situ hardening and moldable bone substitutes. The first in situ hardening bone substitute with clinical application was calcium sulfate. This graft material has been shown to resorb too quickly, leaving residual defects. After three to six weeks $70-90 \%$ of the calcium sulfate is resorbed [9]. The first description of a more promising in situ 
hardening bone substitute was published by Brown and Chow in 1987 [10]. They developed a new calcium phosphate water setting cement, consisting of different calcium phosphates. Since this publication, a variety of in situ hardening calcium phosphate cements, mostly consisting of tetracalcium phosphate (TTCP), dicalcium phosphate anhydride (DCPA), and/or dicalcium phosphate dihydrate (DCPD), have been developed [11,12].

The clinical use of commercially available in situ hardening calcium phosphate cement (CPC) was first described by Constantz et al. [13]. This cement consists of monocalcium phosphate-monohydrate, alpha-tricalcium phosphate, and calcium carbonate. Jubel et al. [14] and Simpson and Andermahr [15] documented the clinical outcome of the treatment of fractures of the tibial plateau, while Cassidy [16] reported the treatment of radial fractures with this cement. Wolff et al. [17] described the treatment of bone defects in dental surgery and showed that the resorption of the material is very slow. Resorption in small defects took up to 30 months. Furthermore, Welkerling et al. [18] documented the results of magnetic resonance tomography following operative treatment of bone cysts. In some cases, an edema of the soft tissue surrounding the defect area was detectable.

Another in situ setting CPC, consisting of alpha-tricalcium phosphate, calcium hydrogene phosphate, calcium carbonate, and precipitated HA was examined by Frankenburg et al. [19], Knaack et al. [20], and Ooms et al. [21]. These studies showed that the resorption of this CPC seems to be faster than by the CPC mentioned above.

One important approach for bone healing and bone ingrowth is the use of growth factors. Growth factors like bone morphogenetic proteins (BMPs), transforming growth factor $\beta$ (TGF- $\beta$ ), insulin-like growth factor (IGF), and fibroblast growth factor (FGF) act as local regulators of cellular activity and are potent mitogenes.

While TGF- $\beta$, IGF, and FGF have osteostimulative effects, BMP improves bone formation by osteoinduction. The BMP-family consists of 42 different BMPs. In osseous tissue BMP-1, BMP-2, and BMP-7 play important roles. BMP-2 is well known as an osteoinductive protein improving bone formation in critical size defects. But BMP-2, as well as other growth factor, requires a carrier for local application. The combination of BMP-2 and a carrier avoids rapid diffusion, while controlling the release kinetics. Hollinger and Leong [22] and Friess et al. [23] documented the efficacy of a collagen-based carrier for BMP-2. Another suitable carrier is demineralized bone matrix [24,25]. But both collagen-based carriers and demineralized bone matrix provide insufficient compressive strength to stabilize osseous defects. 
Furthermore, they are not osteoconductive, which is an important characteristic for bone substitutes.

Niedhart et al. [26] documented enhanced callus formation and mechanical stability of a BMP-2/TCP-composite with a content of $0.25,2.5$, and $25 \mu \mathrm{g}$ BMP-2 in a rat model.

The aim of our study was to determine the effects of an in situ hardening rhBMP-2/TCP-composite with a content of $200 \mu \mathrm{g}$ rhBMP-2 in a critical size defect in a sheep model.

\section{MATERIALS AND METHODS}

\section{TCP-cement}

The self-hardening and resorbable TCP-cement was a generous gift from SBM (Lourdes, France). The cement used in this study was prepared from two tricalcium phosphate precursor powders (part A and B). Part A consists of $500 \mu \mathrm{g}$ of dense, sintered $\beta$-TCP granules (size 300-900 $\mu \mathrm{m}$ ), and part B consists of $500 \mu \mathrm{g} \mathrm{CaSO}_{4} \cdot 0.5 \mathrm{H}_{2} \mathrm{O}$. It was sterilized by $\gamma$-irradiation (25 Gy).

After adding $200 \mu \mathrm{L}$ of isotonic phosphate-buffered saline (PBS, $\mathrm{pH}$ 7.2) per $\mathrm{cm}^{3}$ calcium phosphate with or without $200 \mu \mathrm{g}$ rhBMP-2 (see below) to part A, the composite was mixed energetically for $10 \mathrm{~s}$. Then, part B was added and the conglomerate was stirred with a spatula for $15-30 \mathrm{~s}$. After mixing, the TCP-cement with a total amount of $1 \mathrm{~cm}^{3}$ was ready to use. It hardens within $5-10 \mathrm{~min}$ in an isotherm reaction and is completely stable after $12-24 \mathrm{~h}$ [27]. After complete hardening $\mathrm{X}$-ray diffraction analysis showed results similar to those described for other $\beta$-TCPs [28] with a slightly increased base rate of amorphous material, which might be due to the needle-like calcium sulfate. Calcium sulfate itself could not be detected in X-ray diffraction analysis. The cement consists mainly of pure $\beta$-TCP (Whitlockite) with small bridges consisting of calcium sulfate.

\section{rhBMP-2}

The rhBMP-2 was obtained from the Institute of Physiologic Chemistry, Würzburg, Germany [29]. For preparation, the cDNA coding for amino acids 283-396 of the mature part of BMP-2 plus an $\mathrm{N}$-terminal Met-Ala extension was amplified by PCR. After transformation of Escherichia coli strain 15 M, BMP-2 synthesis was induced by addition of $1 \mathrm{mM}$ isopropyl-thio- $\beta$-D-glucopyranoside. The BMP-2 was prepared from inclusion bodies. After extraction $(50 \mathrm{mM}$ Na-acetate, 
$\mathrm{pH} 5 ; 8 \mathrm{M}$ urea; $14 \mathrm{mM}$ 2-mercaptoethanol) at room temperature overnight and exhaustive dialysis against water, the protein was refolded, concentrated, and enriched by CM-Sepharose chromatography. It was finally purified by FPLC (Fractogel $\mathrm{EMD} \mathrm{SO}_{3} 650 ; 50 \mathrm{mM}$ sodium acetate, $\mathrm{pH} 5 ; 30 \%$ 2-propanol) eluting with a $\mathrm{NaCl}$ gradient from 0 to 1.5 M. After dialysis against water, the protein was freeze/dried and stored at $-20^{\circ} \mathrm{C}$ [29].

The lyophilized rhBMP-2 was dissolved in sterile distilled water and stored at $-70^{\circ} \mathrm{C}$ until use. Before use, the stock solution was diluted in PBS. We choose a concentration of $200 \mu \mathrm{g}$ rhBMP-2 on the basis of our in vitro assays with human osteoblast-like cells, our results from experiments in rats [26] and the known literature [30].

\section{Operative Procedure}

The procedure was performed as previously described by Niedhart et al. [27]. Twenty adult male Merino-Mix sheep, weight $45-55 \mathrm{~kg}$, were included in this study. National Institutes of Health guidelines (NIH publication \#85-23, Rev. 1985) and the German regulations for the care and use of laboratory animals were observed. The study was approved by the local chapter of National Animal Health Committee.

A trepanation defect of $9.4 \mathrm{~mm}$ diameter and $10 \mathrm{~mm}$ depth was placed in the femoro-patellar groove of both hind limbs, to reduce the number of animals, as a non-weight bearing model. The defects were filled with autologous bone graft, pure TCP, rhBMP-2/TCP-composite, or left empty. Ten defects were evaluated per group.

All animals were anesthetized with halothane (Hoechst, Frankfurt, Germany). As prophylaxis amoxicillin (AmpiSleecol ${ }^{\circledR}$, Albrecht, Aulendorf, Germany) was administered prior to surgery. Both hind limbs were shaved and prepared for surgery. After arthrotomy of the knee and dislocation of the patella medially, a circular trepanation defect (9.4 $\mathrm{mm}$ diameter, $10 \mathrm{~mm}$ depth) was made with a diamond bone cutting system (Scientific Development Systems, München, Germany) in the femoro-patellar groove approximately $2 \mathrm{~cm}$ from the intercondylar notch and filled with $1 \mathrm{~cm}^{3}$ TCP-cement or rhBMP-2/TCP-composite. The cement with or without rhBMP-2 hardened within $5 \mathrm{~min}$ under pressure. As controls, autologous bone graft harvested from the contralateral site was implanted, or the defect was left empty. All defects were closed with bone wax (Ethicon, Norderstedt, Germany). After rinsing the knee joint, incisions were closed with absorbable sutures. Unrestricted activity and weight-bearing were allowed postoperatively. 
Postoperative analgesia was carried out with intramuscular injections of novamine sulfone [27].

\section{Analysis}

During the study period, the animals were physically examined at regular intervals with focus on weight bearing, infections or adverse reactions. Radiological examination was performed postoperatively, after 7 and 12 weeks and analyzed descriptively.

After 12 weeks, the animals were euthanized by an overdose of pentobarbital (Narcoren ${ }^{\circledR}$, Rhone Merieux, Germany) and KCI. The distal femora were carefully dissected free from soft tissue and bone cubes of $1.5 \mathrm{~cm}$ edge length were cut around the defects. These cubes were fixed in $10 \%$ neutral-buffered formalin, not decalcified, and embedded in methylmetacrylate. From the embedded cubes sections were obtained with a diamond saw and polished to 20 or $100 \mu \mathrm{m}$. Contact microradiographs were taken with high-resolution photoemulsion plates (206K1A, Microchrome Technology, San Jose, CA) in a high resolution X-ray machine (Faxitron ${ }^{\circledR}$, Hewlett Packard Co., OR) from $100 \mu \mathrm{m}$ sections. $20 \mu \mathrm{m}$ sections were stained with toluidine blue for histological and histomorphometrical analysis, which was carried out by a Quantimed 600S image analysis system (Leica, Germany), interfaced with a Leica DM RX microscope. The defect area, area of new bone formation, area of remaining cement, and area of total mineral content (cement and new bone) were expressed in $\mathrm{mm}^{2}$ and as a percentage of the trepanation defect.

Statistical analysis was supplied by the Institute of Medical Informatics, University of Aachen. The data was evaluated for each group and analysed by the Wilcoxon rank sum test, $p<0.05$ was set as a measure of significance. In the text and the figures presented, mean values, 95\% confidence intervals, and the standard deviation are expressed.

\section{RESULTS}

\section{Clinical and Radiographic Results}

The pure, in situ setting TCP-cement, and the rhBMP-2/TCPcomposite were easy to handle. With the paste-like material a complete filling of the defect was achieved. The addition of rhBMP-2 did not influence the material properties and the setting process. The composite hardened under pressure within 5 min similar to pure TCP. 
All animals survived the study period. Illness or adverse reactions to the implant material or the applied medication were not observed. The animals did not show abnormal gait one week postoperatively. The postoperative radiographs showed the defects completely filled in both cement groups (Figure 1). Autologous bone graft showed a density similar to the surrounding bone. After 7 weeks, the analysis of the $\mathrm{X}$-rays showed a reduced structural density in the defects filled with the rhBMP-2/TCP-composite in comparison to pure TCP, as sign of increased resorption (Figure 2). This effect decreased after 12 weeks, but was still recognizable (Figure 3). There was no sign of osteolysis or osteosclerosis.

Ossifications were not found in the intra-articular or surrounding tissues.

\section{Microradiography}

Analysis of the microradiographical results showed only a small amount of newly formed bone at the rim of the untreated defects, proving that the defect had a critical size. Defects treated with autologous bone graft were filled with trabecular bone similar to bone

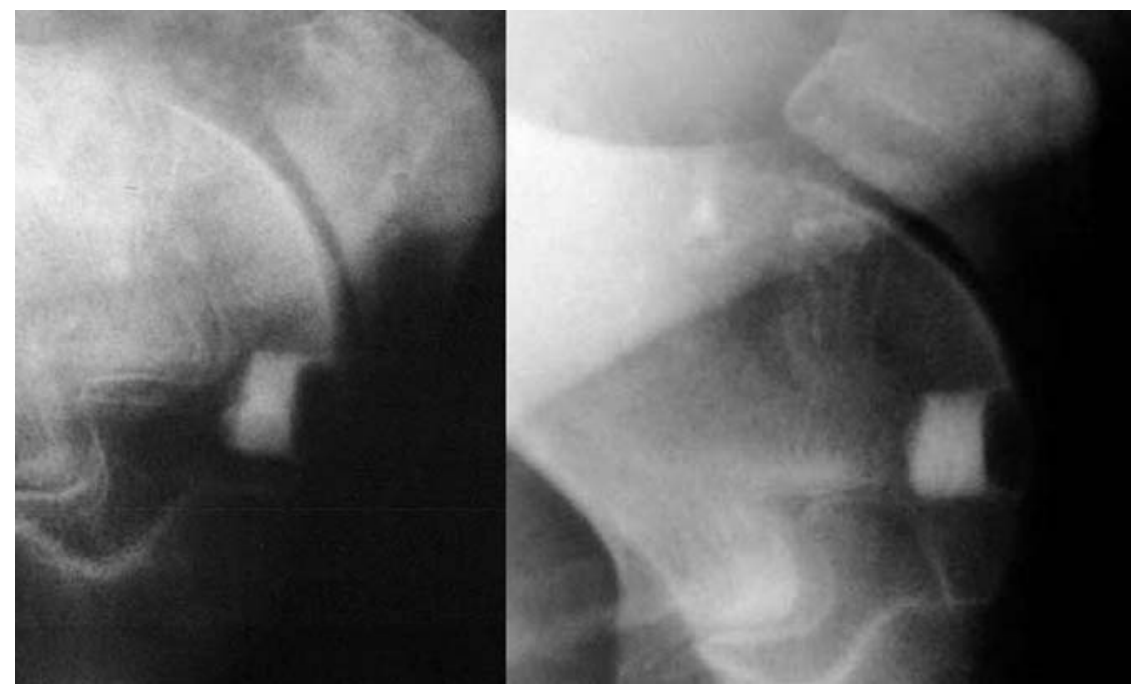

Figure 1. Radiological examination, postoperative: Complete filling of the defect with pure TCP (left) and the rhBMP-2 composite (right). Dense structure of the implanted material. 

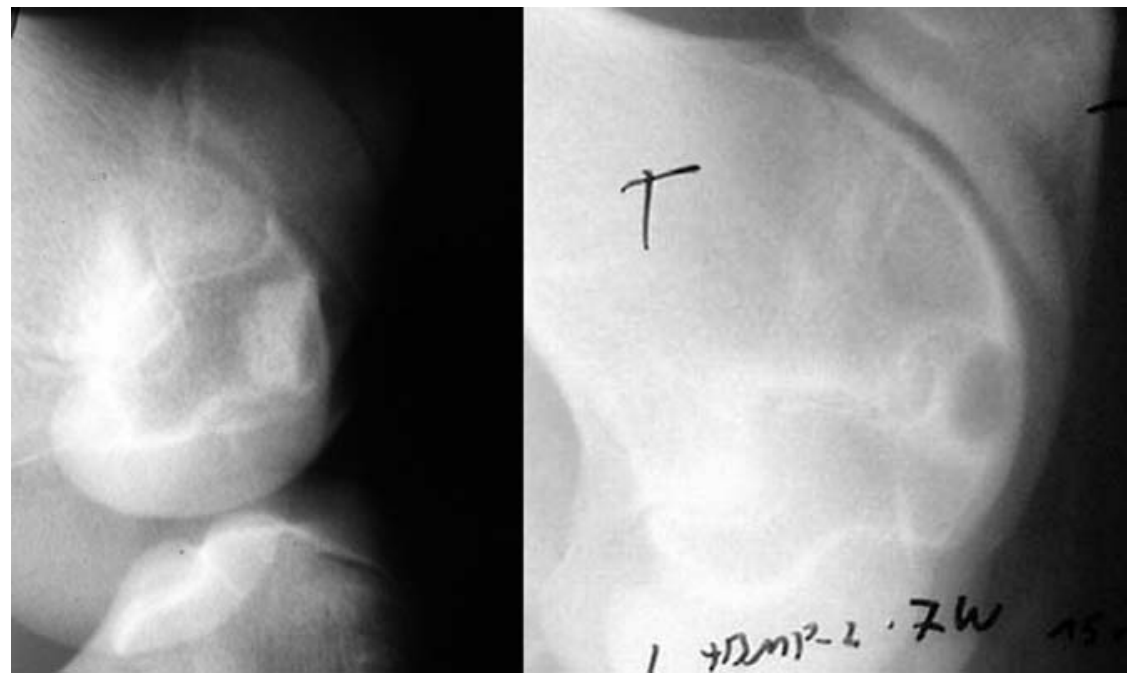

Figure 2. Radiological examination after 7 weeks: weaker and less dense structure of the defect filled with the rhBMP-2/TCP composite (right) in comparison to pure TCP (left).
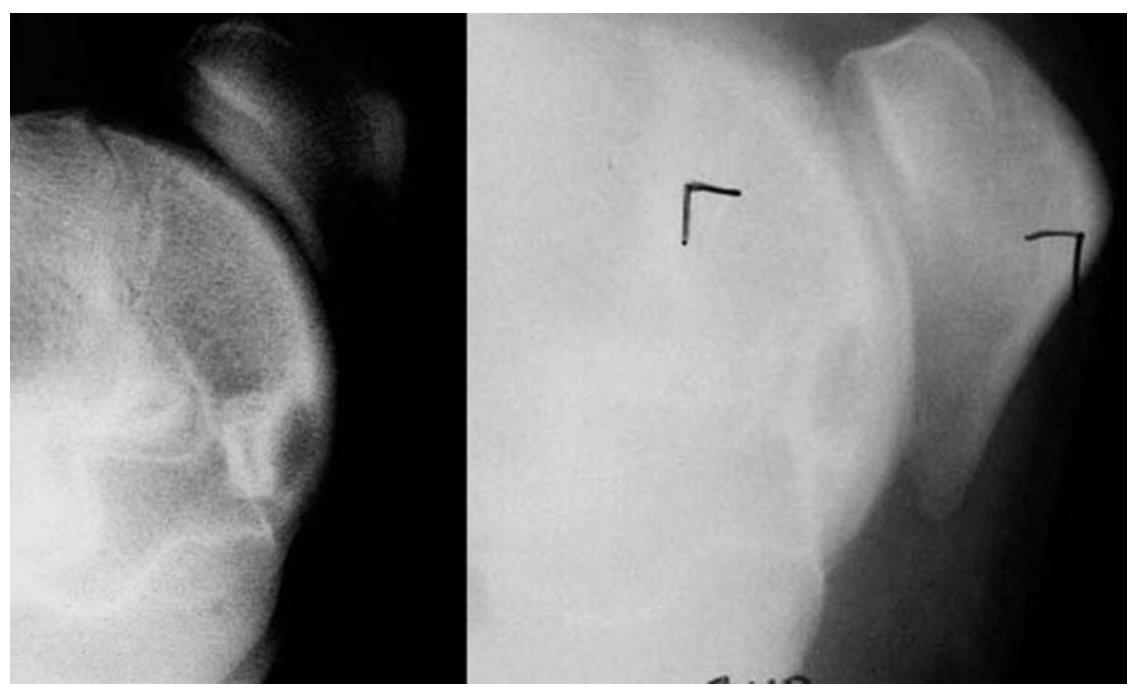

Figure 3. Radiological examination after 12 weeks: nearly complete resorption of the rhBMP-2/TCP composite (right) in comparison to pure TCP (left). 
in the periphery. Discrimination between newly formed and transplanted bone was not possible. Inside the defects treated with pure TCP, newly formed bone was detectable in close contact to TCP-particles, which were uniformly distributed over the defect area. Defects treated with the composite showed similar results, but the amount of remaining cement particles was reduced in comparison to pure TCP.

\section{Histological Results}

Previous publications from our group documented the complete filling of the defects without leakage and a close contact between cement and surrounding bone immediately following surgery (Figure 4) [27]. After 12 weeks most of the pure TCP-cement was resorbed and the defects had remodeled with a trabecular structure. Defects filled with autologous bone graft also showed a trabecular bone structure. Signs of bone resorption were not documented and the original defects were difficult to detect. The results for the rhBMP-2/TCP-composite were similar, but inside the defects less cement remained in comparison to pure TCP (Figure 5). No fibrous interlayer was found between the remaining particles of pure TCP or the rhBMP-2/TCP-composite and the newly formed bone. Cement and bone were in direct contact. Adverse reactions were not detectable. The empty control defects showed only a small amount of ingrown bone originating from the rim of the defect, indicating that this defect had a critical size.

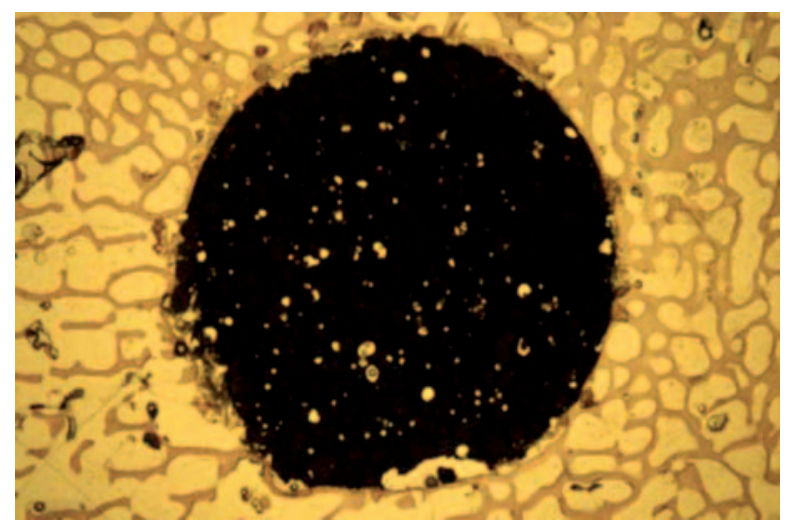

Figure 4. Histology after surgery, complete filling of the defect without leakage and close contact to the surrounding bone (toluidine blue staining, $6,3 \times$ ). 


\section{Histomorphometric Results}

Postoperatively the amount of cement inside the defects was $94 \%$. After 12 weeks, the majority of the cement was resorbed (Table 1). In the pure TCP group, the amount of remaining cement was significantly higher in comparison to the rhBMP-2/TCP-composite treated defects $(p<0.05)$.

The bone content inside the defects treated with the rhBMP-2/TCPcomposite was significantly decreased in comparison to pure TCP $(p<0.05)$ and autologous bone graft $(p<0.05)$.

The total mineral content, which describes the sum of all the calcified structures (bone plus cement), revealed values for the rhBMP-2/TCP-composite group equal to the bone content (newly formed plus transplanted bone) found inside the defects treated with autologous bone graft (Table 1, Figure 6).

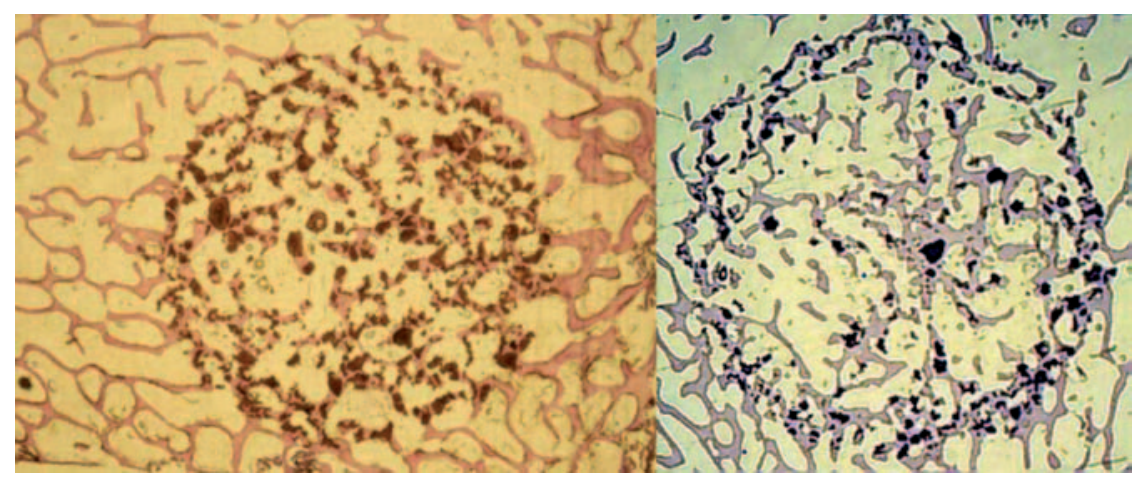

Figure 5. Histology after 3 months: trabecular bone inside both defects, less cement particles in the defect treated with rhBMP-2/TCP composite (right) than in the defect treated with pure TCP (left) (toluidine blue staining, 6,3×).

Table 1. Histomorphometry: results in percent of the defect area. Significant differences between all groups $(p<0.05)$.

\begin{tabular}{lcccc}
\hline & $\begin{array}{c}\text { Untreated } \\
\text { defect }\end{array}$ & $\begin{array}{c}\text { Autologous } \\
\text { bone graft }\end{array}$ & TCP & TCP + BMP-2 \\
\hline Bone content & $5.1 \%$ & $20.0 \%$ & $25.2 \%$ & $15.6 \%$ \\
Cement content & 0 & 0 & $11.3 \%$ & $5.6 \%$ \\
Total mineral content & $5.1 \%$ & $20.0 \%$ & $36.5 \%$ & $21.2 \%$ \\
\hline
\end{tabular}




\section{DISCUSSION}

The treatment of large osseus defects and the search for alternatives to autologous bone graft is a continuing challenge for researchers. In 1965 Urist [31] discovered the osteoinductive properties of a protein, called bone morphogenetic protein (BMP). Further investigations of factors influencing bone growth showed that bone remodeling depends on several growth factors, for example transforming growth factor- $\beta$ (TGF- $\beta$ ), basic fibroblast growth factor (bFGF), insulin-like growth factor (IGF), and BMP. With the exception of the BMPs, which have osteoinductive properties, these proteins have an osteostimulative effect. The group of BMPs consists of different proteins. However, bone growth is mainly influenced by BMP-2 and BMP-7. BMP-2 needs a carrier for the induction of bone formation. The carrier should be biocompatible, osteoconductive, and resorbable.

For evaluation of bone substitutes, a critical size defect is necessary. Our group documented, that the used model of a trepanation defect in the femoro-patellar groove of sheep is a critical size defect. The bone content of the empty control defects was $5 \%$, measured by histomorphometry. Histology of these defects showed only a small amount of newly formed bone at the rim of the defects. This proves, that the model is suitable for the in vivo examination of bone substitutes.

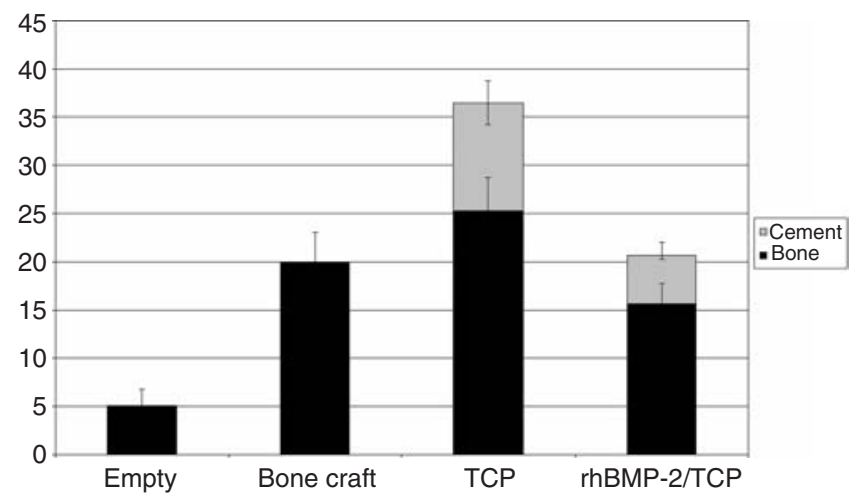

Figure 6. Histomorphometry after 12 weeks: results expressed in percentage of the defect area. Significantly higher bone content in the group treated with pure TCP in comparison to autologous bone graft and the rhBMP-2/TCP composite. Decreased ratio of the cement to bone in the rhBMP-2/TCP composite group. Similar content of calcified tissue in the groups treated with autologous bone graft and the composite. 
In 1987, Urist et al. [32] documented an increased incorporation of tricalcium phosphate discs after addition of BMP-2. While discs without BMP-2 were not integrated in the surrounding bone leading to formation of chronic inflammatory tissue in the periphery of the discs, the addition of growth factor led to a trabecular ingrowth of bone after 4 months without inflammatory reaction. Levine et al. [33] implanted t-shaped HA bodies supra- and subperiosteally with and without $100 \mu \mathrm{g}$ BMP-2 and fixed the implants deep to the auricularis anterior muscle of rabbits for development of bone flaps in reconstructive surgery. They documented increased bone formation inside the subperiosteally implanted HA/BMP-2-composite in comparison to pure HA and the supraperiosteally implanted material. Allegrini et al. [34] examined the effect of $500 \mu \mathrm{g}$ BMP-2 with a HA carrier in a rabbit sinus lift. They found increased bone formation up to $33.3 \%$ in relation to controls. Hoshino et al. [35] loaded $\beta$-TCP cylinders with $25 \mu \mathrm{g}$ BMP-2 and implanted these cylinders in a rib defect of dogs. They reported increased bone formation and bony ingrowth into the bone substitute. Ohyama et al. [30] investigated the interbody fusion rate in canine lumbar spine utilizing a composite consisting of $200 \mu \mathrm{g}$ BMP-2 and $\beta$-TCP. The rate of complete fusions increased in this study in comparison to controls. Paul and Sharma [36] reviewed various studies dealing with calcium phosphates as a Drug Delivery System (DDS). They found out that calcium phosphates are a suitable carrier for many substances, such as growth factors and antibiotics, but that the effectiveness of such DDS depends mainly on the carrier, the calcium phosphates. They state that the desired release kinetics could be achieved by modifying the ceramic devices. We examined the suitability of the in situ hardening TCP cement in its original form without any modification, because release kinetics of this cement could not be examined in vitro. BMP-2 was incorporated into the TCP cement during mixing and setting. Resorption and subsequent release of the protein was not measurable in vitro. The analysis of the release kinetics without resorption of the calcium phosphate showed no protein release.

The dose- and carrier-dependence of BMP-2 was shown by Barnes et al. [37]. They used 3 (final concentration $0.6 \mathrm{mg} \mathrm{mL}^{-1}$ ) and $10 \mathrm{mg}$ per side (final concentration $2.0 \mathrm{mg} \mathrm{mL}^{-1}$ ) BMP-2 in combination with a calcium phosphate carrier (15\% HA, $85 \% \beta-\mathrm{TCP} /$ collagen matrix) and $3 \mathrm{mg}$ per side $\left(1.5 \mathrm{mg} \mathrm{mL}^{-1}\right)$ BMP-2 with an absorbable collagen sponge around the calcium phosphate carrier as bulking agent in a spine fusion model in non-human primates. The results showed that complete fusion was achieved with $10 \mathrm{mg}$ per side BMP-2 applied via the calcium phosphate carrier and $3 \mathrm{mg}$ per side BMP-2 in the absorbable collagen 
sponge around the calcium phosphate, while $3 \mathrm{mg}$ per side BMP-2 with the calcium phosphate carrier failed. In this context, the study of Yuan et al. [38] showed that the effect of BMP-2 is limited, so that higher doses have no further osteoinductive effect. They documented increased bone formation when increasing the dosage from 1 to $10 \mu \mathrm{g}$ BMP-2 in a calcium phosphate carrier, while the application of $40 \mu \mathrm{g}$ BMP-2 lead to no further increase, revealing results similar to the $10 \mu \mathrm{g}$ group.

Our study showed trabecular bone ingrowth into defects treated with a composite of $200 \mu \mathrm{g}$ rhBMP-2 and an in situ hardening, moldable and resorbable $\beta$-TCP. Histological analysis showed a direct contact between the newly formed bone and remaining TCP-particles, which were distributed equally over the defects in groups treated with and without BMP-2. Niedhart et al. [27] documented an osteoconductive effect of the pure TCP-cement. The bone content inside the defects treated with the rhBMP-2/TCP-composite was decreased in comparison to pure TCP in histomorphometrical studies. In contrast to the literature, BMP-2 had no osteostimulative effect in addition to the osteoconductive effect of pure TCP. But the bone content in defects treated with the rhBMP-2/ TCP-composite was equal to defects treated with autologous bone. These defects had trabecular bone content similar to bone in the periphery of the defects, which documented complete remodeling of the defects. This is why we conclude, that the addition of rhBMP-2 leads to a faster remodeling of the defects with properties similar to regular bone.

However, the question remains: Why did BMP-2 have no further osteoinductive effect?

One reasonable explanation may be that the dense structure of the composite prohibited the ingrowth of bone in the early phase after implantation, when the maximal dose of BMP-2 was released. Uludag et al. [39] showed that up to $80 \%$ of the BMP-2 is released from its carrier during the first $48 \mathrm{~h}$. Transferring these results to our study means that nearly $160 \mu \mathrm{g}$ BMP-2 was released from the composite during the first $48 \mathrm{~h}$. But in contrast to other bone substitutes with a defined macro- and microporosity, this in situ hardening bone cement has a dense structure directly after implantation. At this time, the defects were filled up to $94 \%$ with the cement fraction of the composite. But the bone ingrowth depends on the macro- and microporosity of a bone substitute, which was limited in the cement immediately following implantation. So the ingrowth of bone and blood vessels may have been hampered by the lack of space inside the defect, reducing the osteoinductive effects of BMP-2.

Additionally, Nakade et al. [40] documented, that high extracellular calcium content inhibits the formation of osteoclast-like cells and 
stimulates osteoblast proliferation. This could clarify the results of the pure TCP-group, while at the same time explaining the formation of osteoclast-like cells and the subsequently increased cement resorption caused by BMP-2.

Another reasonable explanation for the effects documented by Niedhart et al. [27] and the present study is that resorption of the TCP by osteoclasts and the chemical dissolution increased the extracellular calcium content, leading to inhibition of osteoclast-like cells and resulting in higher residual cement content after three months than in the pure TCP group. This explanation is underlined by the findings of Manjubala et al. [41], who documented increased bone formation inside defects filled with a biphasic calcium phosphate ceramic. This ceramic consists of 45\% TCP and 55\% HA. This combination was chosen in order to achieve a more consistent resorption than seen with pure TCP. They discussed a stimulative effect on osteoblasts by the release of calcium ions during the chemical dissolution of the TCP compound. The properties of the TCP-cement investigated in our study were similar but consistent resorption of the cement was achieved by combining dense TCP-particles with small bridges formed by calcium sulfate. We suggest that the significant differences of cement resorption between the groups were a sign of consistent and reliable degradation.

Simultaneously, the increased extracellular calcium content stimulates the proliferation of osteoblasts, as shown by histomorphometry of the bone content inside the defects treated with pure TCP.

Kaneko et al. [42] investigated the effect of BMP-2 on osteoclasts. They showed that BMP-2 induces the differentiation of osteoclast-like cells in mature rabbit osteoclast-like cell culture and elevated the messenger RNA expressions of cathepsin $\mathrm{K}$ and carbonic anhydrase II, which are key enzymes for the degradation of organic and inorganic bone matrices. This would explain why the cement content in the rhBMP-2/TCP-composite group was lower than in the group treated with pure TCP. The increased osteoclast-like cell formation itself probably led to the resorption of the newly formed bone induced by rhBMP-2.

In conclusion, these competitive effects regulated bone formation and resorption of the cement resulting in a faster remodeling of the defect.

According to the dose dependence of BMP-2, we annotate in our in vitro analysis (data not shown), that the dose of $200 \mu \mathrm{g}$ rhBMP-2 was the most effective and that the protein was active. It was not possible to evaluate the in vitro release kinetic of rhBMP-2 from the TCP-cement. 
Although, a first analysis showed that there was no measurable amount of rhBMP-2 to be found without simultaneous resorption of cement. Uludag et al. [39] and Agrawal et al. [43] reported that there is an early burst out effect of BMP-2 in the first $48 \mathrm{~h}$ followed by a significant lower elution rate. Furthermore, Uludag et al. [44] documented a carrier dependence of this effect. They investigated four different carrier materials: collagen, glycolic acid, demineralized bone matrix, and bovine bone material. In their study, collagen had the highest release rate, while TCP had a release rate of $30 \%$. In contrast to this study and most studies focusing on BMP-2 and bone substitutes, in our setup the rhBMP-2 was added during the mixing process of this cement, and not via a soaking process, leading to even distribution of the growth factor over the whole defect. The consequence of incorporation of BMP-2 into the TCP-cement may have been that the growth factor was continuously released during the resorption process in lower doses.

\section{CONCLUSION}

This rhBMP-2/TCP-composite leads to a faster remodeling of stable bone defects and may be useful in clinical applications requiring a quick remodeling at a non-weight bearing site and in situations where autologous bone graft is not available in the required quantity.

\section{REFERENCES}

1. Parikh, S.N. (2002). Bone Graft Substitutes in Modern Orthopaedics, Orthopedics, 25(11): 1301-1309.

2. Tomford, W.W. (2000). Bone Allografts: Past, Present and Future, Cell and Tissue Banking, 1: 105-109.

3. Friedlaender, G.E. (1987). Current Concepts Review: Bone Grafts, The Journal of Bone and Joint Surgery, American Volume, 69A: 786-790.

4. Ahlmann, E., Patzakis, M., Roidis, N., Sheperd, L. and Holtom, P. (2002). Comparison of Anterior and Posterior Iliac Crest Bone Graft in Terms of Harvest-Site Morbidity and Functional Outcomes, The Journal of Bone and Joint Surgery, American Volume, 84A: 716-720.

5. Goulet, A., Senunas, L.E., De Silva, G.L. and Greenfield, M.L.V.H. (1997). Autogenous Iliac Crest Bone Graft. Complications and Functional Assessment, Clinical Orthopaedics and Related Research, 339: 76-81.

6. Vaccaro, A.R. (2002). The Role of Osteoconductive Scaffold in Synthetic Bone Grafts, Orthopedics, 25(5): S571-S578.

7. Damien, C.J. and Parsons, J.R. (1991). Bone-graft and Bone-graft Substitutes - A Review of Current Technology and Applications, Journal of Applied Biomaterials, 2(3): 187-208. 
8. Lu, J., Descamps, M., Dejou, J., Koubi, G., Hardouin, P., Lemaitre, J. and Proust, J.P. (2002). The Biodegradation Mechanism of Calcium Phosphate Biomaterials in Bone, Journal of Biomedical Materials Research, 63: 408-412.

9. Peltier, L.F. and Jones, R.H. (1978). Treatment of Unicameral Bone Cysts by Curettage and Packing with Plaster-of-Paris Pellets, The Journal of Bone and Joint Surgery, American Volume, 60A: 820-822.

10. Brown, C.E. and Chow, L.C. (1987). A New Calcium Phosphate Water Setting Cement, In: Brown, P.W. (ed.), Cements Research Progress 1986, pp. 352-379, American Ceramic Society, Westerville.

11. Fukase, Y., Eanes, E.D., Takagi, S., Chow, L.C. and Brown, W.E. (1990). Setting Reactions and Compressive Strengths of Calcium Phosphate Cements, Journal of Dental Research, 69: 1852-1856.

12. Ishkawa, K., Takagi, S., Chow, L.C. and Ishkawa, Y. (1995). Properties and Mechanisms of Fast-Setting Calcium Phosphate Cements, Journal of Materials Science: Materials in Medicine, 6: 528-533.

13. Constantz, B.R., Ison, I.C., Fulmer, M.T., Poser, R.D., Smith, S.T., VanWagoner, M., Ross, J., Goldstein, S.A., Jupiter, J.B. and Rosenthal, D.I. (1995). Skeletal Repair by In situ Formation of the Mineral Phase of Bone, Science, 267: 1796-1799.

14. Jubel, A., Andermahr, J., Mairhofer, J., Prokop, A., Hahn, U. and Rehm, K.E. (2004). Use of the Injectable Bone Cement Norian SRS for Tibial Plateau Fractures. Results of a Prospective 30-months Follow-up Study, Der Orthopade, 33(8): 919-927.

15. Simpson, D. and Keating, J.F. (2004). Outcome of Tibial Plateau Fractures Managed with Calcium Phosphate Cement, Injury, 35: 913-918.

16. Cassidy, C., Jupiter, J.B., Cohen, M., Delli-Santi, M., Fennell, C., Leiberry, C., Husband, J., Ladd, A., Seitz, W.R. and Constantz, B. (2003). Norian SRS Cement Compared with Conventional Fixation in Distal Radial Fractures. A Randomized Study, The Journal of Bone and Joint Surgery, American Volume, 85A: 2127-2137.

17. Wolff, K.D., Swaid, S., Bockmann, R.A., Holzle, F. and Muller-Mai, C. (2004). Degradable Injectable Bone Cement in Maxillofacial Surgery: Indications and Clinical Experience in 27 Patients, Journal of CranioMaxillofacial Surgery, 32: 71-79.

18. Welkerling, H., Raith, J., Kastner, N., Marschall, C. and Windhager, R. (2003). Painful Soft-Tissue Reaction to Injectable Norian SRS Calcium Phosphate Cement after Curettage of Enchondromas, The Journal of Bone and Joint Surgery, British Volume, 85B: 238-239.

19. Frankenburg, E.P., Goldstein, S.A., Bauer, T.W., Harris, S.A. and Poser, R.D. (1998). Biomechanical and Histological Evaluation of a Calcium Phosphate Cement, The Journal of Bone and Joint Surgery, American Volume, 80A: 1112-1124.

20. Knaack, D., Goad, M.E.P., Aiolova, M., Rey, C., Tofighi, A., Chakravarty, P. and Lee, D.D. (1998). Resorbable Calcium Phosphate Bone Substitutes, Journal of Biomedical Materials Research Part B: Applied Biomaterials, 43: 399-409. 
21. Ooms, E.M., Wolke, J.G., van de Heuvel, M.T., Jeschke, B. and Jansen, J.A. (2003). Histological Evaluation of the Bone Response to Calcium Phosphate Cement Implanted in Cortical Bone, Biomaterials, 24: 989-1000.

22. Hollinger, J.O. and Leong, K. (1996). Poly(alpha-hydroxy acids): Carriers for Bone Morphogenetic Proteins, Biomaterials, 17: 187-194.

23. Friess, W., Uludag, H., Foskett, S., Biron, R. and Sargant, C. (1999). Characterization of Absorbable Collagen Sponges as rhBMP-2 Carriers, International Journal of Pharmaceutics, 187: 91-99.

24. Yasko, A.W., Lane, J.M., Fellinger, E.J., Rosen, V., Wozney, J.M. and Wang, E.A. (1992). The Healing of Segmental Bone Defects, Induced by Recombinant Human Bone Morphogenetic Protein (rhBMP-2), The Journal of Bone and Joint Surgery, American Volume, 74A: 659-670.

25. Marden, L.J., Hollinger, J.O., Chaudhari, A., Turek, T., Schaub, R.G. and Ron, E. (1994). Recombinat Human Bone Morphogenetic Protein-2 is Superior to Demineralized Bone Matrix in Repairing Craniotomy Defects in Rats, Journal of Biomedical Materials Research, 28: 1127-1138.

26. Niedhart, C., Maus, U., Redmann, E., Schmidt-Rohlfing, B., Niedhart, F.U. and Siebert, C.H. (2003). Stimulation of Bone Formation with an in situ Setting Tricalcium Phosphate/rhBMP-2 Composite in Rats, Journal of Biomedical Materials Research, 65A: 17-23.

27. Niedhart, C., Maus, U., Piroth, W., Miltner, O., Schmidt-Rohlfing, B. and Siebert, C.H. (2004). Evaluation of a Resorbable, in situ Setting Bone Substitute in a Sheep Model, Journal of Biomedical Materials Research Part B: Applied Biomaterials, 71B: 123-129.

28. Weibrich, G., Gnoth, S.-H., Kunkel, M., Trettin, R., Werner, H.-D. and Wagner, W. (1999). X-ray Diffractometry of Bone Regeneration Materials, Mund-, Kiefer- und Gesichtschirurgie, 3, 92-97.

29. Ruppert, R., Hoffmann, E. and Sebald, W. (1996). Human Bone Morphogenetic Protein 2 Contains a Heparin-Binding Site which Modifies its Biological Activity, European Journal of Biochemistry, 237: 295-302.

30. Ohyama, T., Kubo, Y., Iwata, H. and Taki, W. (2004). Beta-tricalcium Phosphate Combined with Recombinant Human Bone Morphogenetic Protein-2: A Substitute for Autograft, used for Packing Interbody Fusion Cages in the Canine Lumbar Spine, Neurologia medica-chirurgica (Tokyo), 44(5): 234-240.

31. Urist, M.R. (1965). Bone Formation By Autoinduction, Science, 150: 893-899.

32. Urist, M.R., Nilsson, O., Rasmussen, J., Hirota, W., Lovell, T., Schmalzreid, T. and Finerman, D.A.M. (1987). Bone Regeneration under the Influence of a Bone Morphogenetic Protein (BMP) Beta Tricalcium Phosphate /TCP) Composite in Skull Trephine Defects in Dogs, Clinical Orthopaedics and Related Research, 214: 295-304.

33. Levine, J.P., Bradley, J., Turk, A.E., Ricci, J.L., Benedict, J.J., Steiner, G., Longaker, M.T. and McCarthy, J.G. (1997). Bone Morphogenetic Protein Promotes Vascularization and Osteoinduction in Preformed Hydroxyapatite in the Rabbit, Annals of Plastic Surgery, 39(2): 158-168. 
34. Allegrini Jr, S., Yoshimoto, M., Salles, M.B. and Konig Jr, B. (2004). Bone Regeneration in Rabbit Sinus Lifting Associated with Bovine BMP, Journal of Biomedical Materials Research Part B: Applied Biomaterials, 68(2): 127-131.

35. Hoshino, M., Egi, T., Terai, H., Namikawa, T. and Takaoka, K. (2006). Repair of Long Intercalated Rib Defects using Porous Beta-Tricalcium Phosphate Cylinders Containing Recombinant Human Bone Morphogenetic Protein-2 in Dogs, Biomaterials, 27(28): 4934-4940.

36. Paul, W. and Sharma, C.P. (2003). Ceramic Drug Delivery: A Perspective, Journal of Biomaterials Applications, 17: 253-264.

37. Barnes, B., Boden, S., Lousi-Ugbo, J., Tomak, P., Park, J., Park, M. and Minamide, A. (2005). Lower Dose of rhBMP-2 Achieves Spine Fusion when Combined with an Osteoconductive Bulking Agent in Non-Human Primates, Spine, 30(10): 1127-1133.

38. Yuan, H., de Bruijn, J.D., Zhang, X., van Blitterswijk, C.A. and de Groot, K. (2001). Use of an Osteoconductive Biomaterial as a Bone Morphogenetic Protein Carrier, Journal of Materials Science, 12: 761-766.

39. Uludag, H., D'Augusta, D., Palmer, R., Timony, G. and Wozney, J.M. (1999). Characterization of rhBMP-2-pharmacokinetics Implanted with Biomaterial Carriers in the Rat Ectopic Model, Journal of Biomedical Materials Research, 46: 193-202.

40. Nakade, O., Takahashi, K., Takuma, T., Aoki, T. and Kaku, T. (2001). Effect of Extracellular Calcium on the Gene Expression of Bone Morphogenetic Protein-2 and -4 of Normal Human Bone Cells, Journal of Bone and Mineral Metabolism, 19(1): 13-19.

41. Manjubala, I., Sastry, T.P. and Suresh Kumar, R.V. (2005). Bone In-growth Induced by Biphasic Calcium Phosphate Ceramic in Femoral Defect of Dogs, Journal of Biomaterials Applications, 19: 341-360.

42. Kaneko, H., Arakawa, T., Mano, H., Kaneda, T., Ogasawara, A., Nakagawa, M., Toyama, Y., Yabe, Y., Kumegawa, M. and Hakeda, Y. (2000). Direct Stimulation of Osteoclastic Bone Resorption by Bone Morphogenetic Protein (BMP)-2 and Expression of BMP Receptors in Mature Osteoclasts, Bone, 27(4): 479-486.

43. Agrawal, C.M., Best, J., Heckman, J.D. and Boyan, B.D. (1995). Protein Release Kinetics of a Biodegradable Implant for Fracture Non-unions, Biomaterials, 16: 1255-1260.

44. Uludag, H., D'Augusta, D., Golden, J., Li, J., Timony, G., Riedel, R. and Wozney, J.M. (2000). Implantation of Recombinant Human Bone Morphogenetic Proteins with Biomaterial Carriers: A Correlation between Protein Pharmacokinetics and Osteoinduction in the Rat Ectopic Model, Journal of Biomedical Materials Research, 50: 227-238. 